A N N A L E S Annales de Bretagne et des Pays de l'Ouest

Anjou. Maine. Poitou-Charente. Touraine

$124-2$ | 2017

Varia

\title{
Trésors enluminés de Normandie
}

\section{Daniel Pichot}

\section{OpenEdition}

Journals

Édition électronique

URL : http://journals.openedition.org/abpo/3674

DOI : $10.4000 / a b p o .3674$

ISBN : 978-2-7535-6497-8

ISSN : 2108-6443

\section{Éditeur}

Presses universitaires de Rennes

Édition imprimée

Date de publication : 30 juin 2017

Pagination : 171-173

ISBN : 978-2-7535-6495-4

ISSN : 0399-0826

\section{Référence électronique}

Daniel Pichot, «Trésors enluminés de Normandie», Annales de Bretagne et des Pays de l'Ouest [En ligne], 124-2 | 2017, mis en ligne le 17 juillet 2017, consulté le 23 septembre 2020. URL : http:// journals.openedition.org/abpo/3674; DOI : https://doi.org/10.4000/abpo.3674 


\section{Comptes rendus}

Hato, Nicolas, JAсов, Marie (dir.), Trésors enluminés de Normandie. Une (re)découverte, Rennes, PUR, 2016, 294 p.

Ce très beau livre édité par les Presses universitaires de Rennes a été conçu pour devenir le catalogue d'une exposition consacrée aux manuscrits enluminés conservés dans les musées de Normandie qui s'est tenue au musée des Antiquités de Rouen. C'est la quatrième exposition de ce genre en France, après celles de Lille, Toulouse et Angers. Comme les précédentes, elle fait suite à une grande enquête menée par L'Institut national d'histoire de l'art. Normalement, ces œuvres sont conservées dans les bibliothèques ou les archives mais, par les hasards de leur histoire, bien des musées en détiennent et, longtemps, ces fonds sont demeurés quelque peu oubliés. L'enquête était donc une nécessité.

Monter une telle exposition suscitait d'importantes difficultés. En effet, ces collections issues pour leur très grande majorité de legs de collectionneurs présentent une grande disparité. Les manuscrits proviennent d'origines géographiques très diverses et une grande variété peut être constatée dans les époques et les titres. Il s'agissait de montrer les enluminures conservées dans les musées normands mais nullement de bâtir une exposition sur l'enluminure normande. La solution adoptée ne manque pas d'originalité et se révèle passionnante. Logiquement, l'accent porte sur ce qui a provoqué la naissance de ces fonds : les collections et les collectionneurs. Le résultat est double : l'exposition offre un beau choix de livres et de feuillets enluminés mais nous ouvre aussi à la redécouverte, au XIX ${ }^{\mathrm{e}}$ siècle, de cet art médiéval par des hommes passionnés qui ont patiemment accumulé ces pièces avant de les léguer à des musées.

Quatre-vingt treize pièces : livres, mais aussi simples feuillets ou même lettrines découpées, victimes de la passion spéculatrice qui a fait dépecer nombre de manuscrits, proviennent de l'ensemble des musées normands, surtout Rouen mais aussi Caen, Fécamp, etc. Le Petit Palais de Paris est aussi concerné car l'une des plus belles collections rouennaises, celle des frères Dutuit, y est déposée.

Un premier chapitre évoque la découverte de l'enluminure médiévale en Normandie. Précoce, elle se dessine dès le début du XIX ${ }^{\mathrm{e}}$ siècle, en partie sous l'influence d'érudits anglais, puis se développe souvent dans le cadre des sociétés savantes. Des publications importantes utilisant les procédés les plus modernes de reproduction font connaître les miniatures mais elles sont alors totalement coupées de leur contexte. Il s'agit d'images, voire de lettrines isolées du texte, ce qui ne donne qu'un aperçu très artificiel de la réalité et sans doute a contribué à encourager le dépeçage de manuscrits pour en tirer des pages mises sous cadre, les transformant en pseudo-tableaux. Les premières éditions en fac-similés débutent rapidement et le manuscrit des Fontaines, très célèbre document du Xvi ${ }^{\mathrm{e}}$ siècle, se distingue car il donne lieu à plusieurs éditions successives de plus en plus précises en raison de la vue qu'il présente de la ville de Rouen avec ses monuments et ses rues. Dans la bonne société se développe alors une véritable mode de l'enluminure, 
véhiculée par des revues comme L'Enlumineur qui propose des modèles inspirant des cartes, menus etc. Des peintres se livrent aussi à de véritables pastiches quand la publicité se saisit de l'enluminure pour vanter des assurances.

Cet engouement favorise l'activité des collectionneurs qui débute très tôt en Normandie. Après des débuts timides à la fin du XvIII siècle, le mouvement s'épanouit au XIXe. Quelques aristocrates fortunés, des bourgeois enrichis dans l'industrie, des conservateurs rassemblèrent alors des collections inégales, selon leurs possibilités, mais aussi en fonction du marché. Amateurs d'art, ils achetaient des manuscrits enluminés parmi d'autres objets. Si certains possédaient d'évidentes connaissances et eurent éventuellement la main heureuse, H. G. Bréard, pourtant peintre de métier, accumula nombre de faux grossiers. Plusieurs furent des bibliophiles éclairés comme E. H. Langlois ou le libraire P.-B. Mancel dont le legs fut exposé longtemps à la mairie de Caen. Sans doute faut-il mettre à part A. P. H. Le Grand, industriel, qui avait créé la liqueur Bénédictine, soi-disant à partir d'un manuscrit légué par un moine de l'abbaye de la Trinité, et qui fonda une collection d'art médiéval qui comprenait des manuscrits. Il l'installa dans le Palais Bénédictine construit à cet effet afin de renforcer la légende de la fameuse boisson. Ces collections purent compter des manuscrits intéressants mais en général peu nombreux et datant surtout de la fin du Moyen Âge, car les manuscrits de cette époque étaient plus abondants sur le marché et le goût favorisait l'art de ces siècles au détriment des précédents jugés d'une facture trop barbare.

Un chapitre à part est réservé aux frères Dutuit, héritiers d'une confortable fortune industrielle à Rouen. Eugène se passionne pour la bibliophilie et devient vite un notable. Il s'investit dans la protection du patrimoine et sauve quelques chefs-d'œuvre du bâti rouennais, mais ses relations avec la municipalité s'enveniment assez vite. Le relais est pris par Auguste. Tous les deux élaborent une vaste collection de plus de 20000 œuvres, dont plus de la moitié d'estampes, réunissant aussi des objets, des vases antiques, des monnaies. On compte 800 manuscrits - ce qui est important - de grande qualité, ce qui est la preuve d'une vraie passion bibliophilique. En 1902, Auguste demeuré sans enfant lègue l'ensemble de la collection à la Ville de Paris au grand dam de la municipalité rouennaise.

Un dernier chapitre dresse le portrait de Léopold Delisle. Normand de naissance, archiviste et bibliothécaire, il fit toute sa carrière à la Bibliothèque nationale dont il assuma la direction durant plus de vingt-cinq ans, jusqu'en 1905. Il accomplit une œuvre considérable de publication et consacra une part de son activité à la recherche sur les manuscrits enluminés, contribuant à éclairer leur histoire. On lui doit nombre d'études, en particulier sur les manuscrits royaux réunis dans les deux volumes des Recherches sur la librairie de Charles $V$. Il se pencha aussi sur la question technique des reproductions, tout en développant l'activité indispensable de catalogage. Sans être collectionneur, il fit entrer à la Bibliothèque nationale des monuments importants et contribua à enrichir les fonds; plus globalement ses travaux contribuèrent au développement des recherches sur les manuscrits enluminés et les artistes médiévaux.

Après ces études des collectionneurs, qui remettent parfaitement en perspective les manuscrits présentés, la partie suivante est consacrée au catalogue des manuscrits. Celui-ci adopte assez logiquement un classement par types, le seul praticable en raison de l'extrême diversité de la collection, tant pour les catégories d'ouvrages que pour leurs origines géographiques. Les ouvrages normands demeurent très minoritaires mais l'ensemble de l'exposition nous fait accomplir un tour d'Europe des principaux centres de production : Paris, la Flandre, l'Italie... Il n'est guère possible dans le cadre de ce compte rendu d'en faire une présentation détaillée aussi nous permettrons-nous plutôt d'insister sur les éléments les plus 
intéressants. Les manuscrits religieux dominent très largement. Quelques belles bibles illustrées, dont celle de l'abbaye de Foucarmont réalisée sans doute au Mans dans la seconde moitié du XIII ${ }^{\mathrm{e}}$ siècle, et des livres liturgiques comme le Bréviaire à l'usage de l'abbaye de Conches ou le missel de la cathédrale de Bayeux évoquent les possessions des institutions normandes. Cependant, l'ensemble le plus marquant reste celui des Livres d'heures qui attirèrent l'attention des collectionneurs et offrent un lot d'une très grande variété : des productions normandes ou du grand Ouest, parisiennes mais aussi flamandes ou même néerlandaises, provençales ou italiennes. On y découvre tous les stades de qualité qui correspondent bien aux fortunes inégales des gens capables de s'offrir de tels objets de piété. Un livre à l'usage de Coutances demeure bien modeste, à côté des réalisations brugeoises marquées par un caractère très commercial sans lien particulier avec un commanditaire mais décorées par des artistes dotés de beaucoup de métier. Par contre, on retiendra la très grande qualité d'un livre réalisé à Venise par Cristoforo Cortese vers 1425-1430 ou des Heures dites Dutuit produites dans un atelier parisien vers 1530-1540. Les manuscrits profanes, beaucoup moins nombreux, ne manquent pas d'intérêt avec les deux Coutumiers de Normandie du XIV ${ }^{\mathrm{e}}$ siècle et surtout Les Faicts et conquestes d'Alexandre le Grand, magnifique manuscrit réalisé à Bruges pour la Librairie du duc de Bourgogne Philippe le Bon. Enfin, un document rare touche la Bretagne, Le trépas de l'hermine regretée, consacré aux funérailles d'Anne de Bretagne. Une section est consacrée aux dépeçages, pages arrachées et lettrines découpées. Cette pratique malheureuse s'est appliquée à de très beaux manuscrits, on peut citer des collections de lettrines italiennes mais surtout une crucifixion entourée de médaillons évoquant la vie du Christ détachée du missel de l'évêque de Dol, Thomas James, commandé par ce dernier au plus grand enlumineur de Florence à la fin du XVe siècle, Attavante degli Attavanti. Le manuscrit se trouve à la bibliothèque de Lyon, seule cette page est au musée du Havre. Ce Missel est un véritable chef-d'œuvre et la crucifixion en constitue sans doute la plus belle page, unissant aux traditions florentines les acquis des peintres flamands. Enfin, une dernière section rassemble quelques incunables pour lesquels on conserva la tradition de l'enluminure. On relèvera un splendide Boèce parisien et surtout un Livre d'heures, lui aussi parisien, décoré avec des estampes d'après Jean d'Ypres et trois gravures sur cuivre de Jean Pichore. Le catalogue se clôt sur un Xénophon imprimé par Henri II Estienne à Genève en 1581 et offert à Jacques VI d'Écosse, une véritable pièce de roi.

La présentation du livre est remarquable : ce catalogue est aussi un beau livre, à lire ou à consulter. Les chapitres, bien documentés, appuyés sur des notes solides, traitent clairement des problèmes et chacun est suivi par une série de notices présentant les documents exposés et où se développent nombre d'informations. Le tout clair, agréable, est aussi un plaisir pour les yeux, les reproductions des miniatures sont remarquables et surtout dans des dimensions suffisamment importantes pour être examinées de près et donner plus de relief au livre. Incontestablement les PUR offrent ici une très belle réussite de la recherche et de l'édition.

Daniel PICHOT

Blanc, William, Le roi Arthur. Un mythe contemporain, Arles, Libertalia, 2016, Préface de Jean-Clément Martin, 576 pages + cahier couleur 32 pages.

William Blanc, médiéviste mais aussi grand connaisseur de la fantasy et de la culture populaire américaine, nous livre une étude à la fois savante, passionnée et 